\title{
Post Caesarean Wound Infection in a Tertiary Level Hospital in Rajasthan
}

\author{
Gazala Parween ${ }^{1}$, Samta Bali Rathore ${ }^{2}$, Ranjana Atal ${ }^{3}$
}

1,2,3 Department of Obstetrics and Gynaecology, Mahatma Gandhi Medical College and Hospital, Jaipur, Rajasthan, India.

\section{ABSTRACT}

\section{BACKGROUND}

Caesarean section is one of the major obstetric surgeries performed to save the lives of mothers and foetuses. Caesarean section like any other surgical intervention may be accompanied by a number of complications, such as surgical site infections (SSI). We wanted to determine the incidence of wound sepsis following caesarean section, factors that contribute to wound sepsis, types of pathogens causing wound sepsis, and the impact of wound sepsis on the duration of hospital stay.

\section{METHODS}

In this prospective study of 450 candidates. Each candidate has been examined thoroughly after taking a detailed history and were followed after caesarean section to look for any wound infection, along with the cause and factors responsible for that. Patients were evaluated for stitch line sepsis, culture and sensitivity in cases of sepsis and increase in duration of hospital stay recorded. Microsoft excel worksheet has been used for data entry and appropriate tests were applied to find significant association. $P$ value $<0.05$ was considered as statistically significant.

\section{RESULTS}

Post caesarean wound infection was found in $6.8 \%$ of patients. It was found to be more in the age group 31 - 35 yrs., more in illiterates, in primiparas, and who had less than 4 ANC visits, was more in hypertensives, and whose $\mathrm{Hb}$ was less than 11 , in those who were in labour, or in those who had more than 3 vaginal examinations, and in those who had ruptured membranes and with meconium stained liquor. More cases were seen with emergency caesarean section.

\section{CONCLUSIONS}

Factors which were statistically significant were patient in labour, increased number of vaginal examinations, ruptured membranes, meconium stained liquor, and emergency caesarean section. Infections can be reduced by thorough precautions, proper antibiotics, and elective caesarean section.

\section{KEY WORDS}

Prolonged Labour, SSI, Meconium Stained Liquor, Caesarean Section
Corresponding Author: Dr. Samta Bali Rathore, 150/25 Shiprapath, Mansarovar, Jaipur - 302020, Rajasthan, India.

E-mail:dr.sbrathore@gmail.com

DOI: $10.14260 /$ jemds/2020/829

How to Cite This Article:

Parween G, Rathore SB. Post caesarean wound infection in a tertiary level hospital in Rajasthan. J Evolution Med Dent Sci 2020;9(50):3778-3782, 10.14260/jemds/2020/829 DOI:

Submission 24-08-2020,

Peer Review 27-10-2020,

Acceptance 03-11-2020,

Published 14-12-2020.

Copyright (C) 2020 Gazala Parween et al. This is an open access article distributed under Creative Commons Attribution License [Attribution 4.0 International (CC BY 4.0)] 


\section{BACKGROUND}

Caesarean section is one of the major obstetric surgeries performed to save lives of mothers and fetuses. ${ }^{1}$ In last few decades, the incidence of caesarean deliveries, has risen dramatically, whether it has been primary or repeated, with an estimated number of worldwide caesarean section was 22.9 million in 2012.2,3 In the year 2018 - 2019 as per data collected by the Union Ministry of Health and Family Welfare under the Health Management Information System (HMIS), was 14 per cent of the total births took place through a C-section. 19 lakh caesarean section took place in India alone out of total 1.3 crores deliveries in public hospitals.

Caesarean sections being a surgical procedure may give rise to a number of complications. SSI being one of them. SSI has significantly decreased in the last three decades. ${ }^{4,5}$ But despite of this decrease, SSI continue to increase due to rise in incidence of caesarean section, despite improvements in hygiene conditions, antibiotics prophylaxis, sterile procedures and other practices. Post-caesarean SSI increases maternal morbidity and mortality.6,7 Their socio-economic condition includes increase in health care cost and prolong maternal hospitalization and may cause psychological distress to women recovering from caesarean section and caring for the newborn at the same time.

Surgery itself is a risk factor for acquisition of infection and overall incidence of SSI in India was found to be $4.17 \%$ in a surgical ward in India. ${ }^{8}$ Low socioeconomic status and malnutrition further surpluses the risk of infection in caesarean sections. Caesarean section compared to vaginal delivery carries 5 to 20 -fold increased risk of infection 9,10

Surgical site infections may necessitate readmission, thus increase hospital bills, delays recovery, prolong hospitalization or outpatient treatment, as well as other morbidities and mortality. The overall average rate of infection in caesarean section wound has been estimated from $3-15 \%{ }^{11-13}$ thereby increasing the morbidity and mortality and causing significant psychological distress to mother and anchoring financial burden to family.

The causative agent of post caesarean wound infection is universal with regional variations. ${ }^{14-17}$

The rate of SSI following caesarean section varies from place to place because of certain intrinsic and extrinsic variables. This includes the patient specific factors like obesity, age, underlying medical conditions like anaemia, hypertension, asthma, diabetes mellitus, immunecompromised states like HIV infection, hypoalbuminemia, and hyperlipidaemia. And also it varies due to medical and health facilities, infrastructure and patient care and management. Other factors include obstetrics specific criteria like preoperative preparation of the patient, type of antibiotic prophylaxis, time interval between membranes ruptured prior to operation, manual extraction of placenta, chorioamnionitis, number of vaginal examinations done before surgery, intraoperative factors like type of anaesthesia, duration of operation, type of skin incision, suture and staples used, transfusion of blood products, grade of operator (consultant / registrar / senior resident), previous caesarean section, and environment of the operation theatre. ${ }^{18,19}$ Evaluation by daily inspection of caesarean incision is an essential part of postoperative care and should be done daily. A high index of suspicion should be observed in patients who present with fever, erythema, tenderness, purulent discharge or induration. ${ }^{20}$ These wound infections become apparently visible around 4 - 7 post op day, when most women has already been discharged from hospital. ${ }^{20}$

In order to reduce the incidence of SSI, targeted prevention strategies need to be implemented to overcome the identified risk factor.

\section{METHODS}

This prospective study has been conducted among 450 pregnant females who delivered by caesarean section in the Department of Obstetrics and Gynaecology of Mahatma Gandhi Medical College and Hospital, Sitapura, Jaipur, from $1^{\text {st }}$ January 2019 to $30^{\text {th }}$ June 2020. Patients who refused to give consent to participate in the study were excluded. Patients were followed for 2 weeks.

\section{Sample Size}

The sample size was calculated using the following formula:

$$
N=\frac{\mathrm{Z} 2 \times \mathrm{P}(1-\mathrm{P})}{\mathrm{D}^{2}}
$$

Where,

$\mathrm{N}=$ Sample size

$\mathrm{Z}=$ the standard error from the mean corresponding to $95 \%$ confidence interval, which is 1.96

$\mathrm{P}=$ the incidence of wound sepsis which is $18 \%$

$\mathrm{D}=$ the absolute precision which is $5 \%(0.05)$

Sample size was 226

Considering $10 \%$ attrition.

A detailed history of these patients has been taken including the age, socioeconomic status, period of gestation, presenting complain including labour pains and PROM, history and number of antenatal visits, parity, any medical and surgical history including history of previous caesarean section.

A thorough general and systemic examination has included pulse rate, B.P., temperature, pallor, per abdominal and per vaginal examination. Antenatal profile including haemoglobin, blood group, GCT, TSH, HIV, Hbs-Ag, VDRL, HCV and urine analysis has been done.

Operative data has been collected including type of anaesthesia, type of incision, type of scrub done, time of surgery, amount of blood loss has been recorded.

Patient has been evaluated for stitch line sepsis, by sending the discharge collected from stitch line for culture and sensitivity (to identify the organism grown and sensitivity for particular antibiotics) and increase in duration of hospital stay recorded.

A preceded structured questionnaire (Proforma) has been used to gather information from the patient.

\section{Statistical Analysis}

Data was entered in Microsoft excel worksheet and Chi-square test has been used to find the significant association. P value < 0.05 was considered statically significant. 


\section{RESULTS}

\begin{tabular}{|ccccc|}
\hline $\begin{array}{c}\text { Age in } \\
\text { years }\end{array}$ & $\begin{array}{c}\text { No. of } \\
\text { Cases }\end{array}$ & Percentage & $\begin{array}{c}\text { Those Who } \\
\text { Developed Infection }\end{array}$ & Percentage \\
$\leq 20$ & 31 & $6.8 \%$ & 2 & $6.4 \%$ \\
$21-25$ & 209 & $46 \%$ & 15 & $7.17 \%$ \\
$26-30$ & 165 & $36 \%$ & 10 & $6.06 \%$ \\
$31-35$ & 35 & $1.5 \%$ & 4 & $11.4 \%$ \\
& \multicolumn{5}{c}{ Educational Status } \\
Illiterate & 45 & $10 \%$ & 7 & $15.5 \%$ \\
$\begin{array}{c}\text { School } \\
\text { Education }\end{array}$ & 204 & $45.3 \%$ & 15 & $7.3 \%$ \\
Graduate & 154 & $34.2 \%$ & 6 & $3.89 \%$ \\
Post Graduate & 47 & $10.4 \%$ & 3 & $6.3 \%$ \\
\hline \multicolumn{5}{c}{ Table 1. Demographic Data } \\
\hline
\end{tabular}

Table 1. Shows larger group of caesarean section is in group of 21 - 25 years (main reproductive age group in Rajasthan) and the infection rate is high in 31 - 35 years age group and large group under study has school education and higher incidence of infection is seen in illiterates.

\begin{tabular}{|c|c|c|c|c|c|}
\hline Parity & $\begin{array}{l}\text { No. of } \\
\text { Cases }\end{array}$ & Percentage & $\begin{array}{c}\text { Those Who } \\
\text { Developed } \\
\text { Infection }\end{array}$ & Percentage & $\begin{array}{c}P \\
\text { Value }\end{array}$ \\
\hline Primiparous & 218 & $48.4 \%$ & 19 & $8.7 \%$ & \\
\hline Multiparous & 232 & $51.5 \%$ & 12 & $5.1 \%$ & \\
\hline \multicolumn{6}{|l|}{ With Previous } \\
\hline $\begin{array}{l}\text { Caesarean } \\
\text { Section }\end{array}$ & 182 & $40.4 \%$ & 9 & $4.9 \%$ & \\
\hline \multicolumn{6}{|c|}{ No. of ANC Visit } \\
\hline$>4$ & 386 & $85.7 \%$ & 26 & $6.7 \%$ & \multirow{2}{*}{$>0.05$} \\
\hline$<4$ & 64 & $14.2 \%$ & 5 & $7.8 \%$ & \\
\hline \multicolumn{6}{|c|}{ Table 2. Obstetric Data } \\
\hline
\end{tabular}

Table 2. Depicts obstetrics data. Large group under study is multiparous, and large no. of wound infection is seen in primiparous and shows large number of cases has more than 4 visits. Percentage of infection is higher in those who has less than 4 visits but this data is statistically not significant.

\begin{tabular}{|c|c|c|c|c|c|}
\hline $\begin{array}{l}\text { Blood } \\
\text { Pressure }\end{array}$ & $\begin{array}{l}\text { No. of } \\
\text { Cases }\end{array}$ & $\%$ age & $\begin{array}{c}\text { Those who } \\
\text { Developed Infection }\end{array}$ & $\%$ age & $\begin{array}{c}P \\
\text { Value }\end{array}$ \\
\hline Normotensive & 387 & $86 \%$ & 24 & $6.2 \%$ & \multirow{2}{*}{$>0.05$} \\
\hline Hypertensive & 63 & $14 \%$ & 7 & $11.11 \%$ & \\
\hline \multicolumn{6}{|c|}{ Haemoglobin } \\
\hline Less than 11 & 190 & $42.2 \%$ & 16 & $8.4 \%$ & \multirow{2}{*}{$>0.05$} \\
\hline More than 11 & 259 & $57.5 \%$ & 15 & $5.7 \%$ & \\
\hline \multicolumn{6}{|c|}{ Table 3. Pre-Operative Status } \\
\hline
\end{tabular}

Table 3. Depicts preoperative status. Greater percentage of wound infection is seen in hypertensive patient which is statistically not significant and larger population has haemoglobin more than 11. Large percentage of infection seen in group whose $\mathrm{Hb}$ is less than 11. It is statistically not significant.

Table 4. depicts percentage of infection is higher in those patient who were in labour which is statistically significant and shows large percentage of infection in those who are in labour for more than $6 \mathrm{hrs}$., large percentage of infection in those who underwent more than 3 times vaginal examination which is statistically significant and large percentage of infected cases in those who has ruptured membranes which is also statistically significant and meconium stained liquor is highly significant for wound infection.

Table 5. Shows that large number of cases are emergency caesarean section, most infective cases seen in emergency caesarean which is statistically significant and infection rate is $6.8 \%$. The largest number of organisms which causes SSI was
MRSA (Methicillin-Resistant Staphylococcus aureus) followed by poly microbial flora followed by $S$ epidermidis and large number of infections occurred on day $4^{\text {th }}$.

\begin{tabular}{|c|c|c|c|c|c|}
\hline Labour & $\begin{array}{l}\text { No. of } \\
\text { Cases }\end{array}$ & $\%$ age & $\begin{array}{c}\text { Those who } \\
\text { Developed Infection }\end{array}$ & $\%$ age & $\begin{array}{c}P \\
\text { Value }\end{array}$ \\
\hline In Labour & 82 & $18.2 \%$ & 13 & $15.8 \%$ & \multirow{2}{*}{$<0.001$} \\
\hline Not in Labour & 363 & $80.6 \%$ & 18 & $4.9 \%$ & \\
\hline \multicolumn{6}{|c|}{ Duration of Labour } \\
\hline $\begin{array}{c}\text { More than } 6 \\
\text { hrs. }\end{array}$ & $45(82)$ & $54.8 \%$ & 8 & $17.7 \%$ & \multirow{2}{*}{$>0.05$} \\
\hline $\begin{array}{c}\text { Less than } 6 \\
\text { hrs. }\end{array}$ & $42(82)$ & $51.2 \%$ & 5 & $11.9 \%$ & \\
\hline \multicolumn{6}{|c|}{ No. of Vaginal Examination } \\
\hline None & 136 & $30 \%$ & 5 & $3.6 \%$ & \multirow{3}{*}{$<0.05$} \\
\hline Less than 3 & 239 & $53.1 \%$ & 14 & $5.8 \%$ & \\
\hline More than 3 & 75 & $16.6 \%$ & 11 & $14.6 \%$ & \\
\hline \multicolumn{6}{|c|}{ Membranes Status } \\
\hline Intact & 318 & $70.6 \%$ & 16 & $5 \%$ & \multirow{2}{*}{$<0.05$} \\
\hline Ruptured & 132 & $29.3 \%$ & 15 & $11.3 \%$ & \\
\hline \multicolumn{6}{|c|}{ Colour of Liquor } \\
\hline Clear & 449 & $99.7 \%$ & 30 & $6.68 \%$ & \multirow[b]{2}{*}{$<0.001$} \\
\hline $\begin{array}{c}\text { Meconium } \\
\text { Stained Liquor }\end{array}$ & 1 & $0.22 \%$ & 1 & $100 \%$ & \\
\hline \multicolumn{6}{|c|}{ Table 4. Partogram Findings } \\
\hline
\end{tabular}

\begin{tabular}{|ccccc|}
\hline $\begin{array}{c}\text { Type of Caesarean } \\
\text { Section }\end{array}$ & $\begin{array}{c}\text { No. of } \\
\text { Cases }\end{array}$ & Infective & $\begin{array}{c}\text { Non- } \\
\text { Infective }\end{array}$ & $\begin{array}{c}\text { P } \\
\text { Value }\end{array}$ \\
\hline Elective & 213 & 8 & 205 & $<0.001$ \\
Emergency & 237 & 22 & 215 & \\
\hline \multicolumn{4}{|r|}{ Table 5. Parameters Related to Caesarean Section } \\
\hline
\end{tabular}

\begin{tabular}{|ccc|}
\hline Micro-Organism & No. of Cases & Percentage \\
MRSA & 5 & $16.12 \%$ \\
Sterile & 6 & $19.3 \%$ \\
Not Sent & 9 & $29 \%$ \\
E. Coli & 2 & $6.4 \%$ \\
Staph. Epidermidis & 2 & $6.4 \%$ \\
Polymicrobial Flora & 4 & $12.9 \%$ \\
Serous & 3 & $9.6 \%$ \\
Day of Sepsis & No. of Wound Sepsis & Percentage \\
On Day 4 & 21 & $67 \%$ \\
Between 4 - 7 & 5 & $16 \%$ \\
After Day 7 & 5 & $16 \%$ \\
\hline Table 6. Micro-Organism Deducted in Culture Report \\
\hline
\end{tabular}

\section{DISCUSSION}

Developing post caesarean wound infection is a traumatic experience as caesarean section has a 5 - 20 times higher risk of local sepsis as compared to vaginal delivery.

The common pathogens found were $S$. aureus, poly microbial flora E.coli. And among which in our study Staphylococcus is the most common cause of postsurgical wound infection. It is important for the caretaker to hand wash regularly and wounds should be dressed in sterile bandages until they heal fully, to avoid any infections from Staphylococcus bacteria,

Satyanarayan et $\mathrm{al}^{21}$ in their study concluded that SSI were 3 times more common in emergency caesarean section as compared to elective caesarean section. In this study, wound infection after elective CS is $3.7 \%$, compared to ${ }^{22} 9.2 \%$ in emergency caesarean section. The probable reason may be the less preoperative preparatory time available for surgery.

In prolonged labour due to frequent vaginal examinations there is increased chances of infection in such cases.

Due to loss of protective effect of the intact fetal membranes, premature rupture of membranes, increases the risk of chorioamnionitis. The greater the time length between 
the rupture of membranes and the caesarean section, the higher is the wound infection, as the amniotic fluid is no longer sterile once the membranes have ruptured and may act as a culture medium and the resultant infection infects the uterine and skin incision. ${ }^{22}$

Departmental policy at Mahatma Gandhi Medical College and Hospital strongly advocates using prophylactic antibiotics, cefotaxime 1 gmi.v. Recent evidences also suggests that preincisional antibiotics is a safe prophylactic measures to reduce maternal morbidity by reducing the incidence of SSI. ${ }^{23}$

Caesarean section wound infection increases maternal morbidity and prolong hospital stay. In Mahatma Gandhi Medical College patients undergoing caesarean delivery with no associated complication are routinely discharged on fourth post-operative day. Surgical site wound infection increases the hospital stay to about 5 - 8 days.

All measures to reduce the risk of infections, should be taken in the pre, intra, and postoperative phases. Preoperative preventive measures will include clipping of operative site, proper autoclaving of surgical instrument and pre-incisional antibiotics. Proper hand washing prior to procedures and preoperatively is important in decreasing the risk of infection despite use of gloves. Glove puncture occurs in as many as 60 $\%$ of all surgical procedures. This risk is increased in direct proportion to needle handling. It's also influenced by emergency procedure, longer operative time, inadequate muscle relaxation, and number of sutures and wound depth. Thus the surgical team bacteria flora is exposed to the incision and the patient's disease exposed to the surgical team. It's also important to adequately prepare surgical site by cleaning and application of suitable antiseptic. Wound healing and outcome may be related to an incision placement. Which relate to a number of factors, the diagnosis, urgency of operation, presence of a previous incision and cosmetic preference. A transverse incision heals with an almost invisible scar and clinically performs. Presence of dead space increases the risk of wound infection and poor outcome. Use of suture material to close the dead space may further increase the risk of infection and poor wound healing.

Achievement of good homeostasis is also important in wound healing. Serum and tissue fluid collect in the incision as a requisite first step in wound repair in the inflammatory phase. However, excessive blood and fluid is not desirable. Blood is an excellent culture medium and the incidence of experimental wound infections relates to the haemoglobin concentration of wound fluid. For achieving wound homeostasis, the electrosurgical cautery is useful.

Pre-operative antibiotics should be given to all patients scheduled for cesarean section whether emergency or elective. In order to reduce the risk of wound sepsis, infection prevention procedure should be followed appropriately. Effort should be done to reduce length of hospital stay after caesarean section. Evaluation and improvement of pre and post-operative care through regular updation of knowledge and training involving supervision of more skilled person.

\section{CONCLUSIONS}

Assessment of risk factors should be done before surgery to determine the incidence and risk of SSI. Modification of these risk factors can reduce the chances of SSI. By rigorous surgical techniques, postoperative wound infection can be greatly reduced and controlled. The frequency of infection can be prevented by public awareness program and regular updation of hospital prevention policies.

Data sharing statement provided by the authors is available with the full text of this article at jemds.com.

Financial or other competing interests: None.

Disclosure forms provided by the authors are available with the full text of this article at jemds.com.

\section{REFERENCES}

[1] Charoenboon C, Srisupundit K, Tongsong T. Rise in caesarean section rate over a 20 -year period in a public sector hospital in northern Thailand. Arch Gynecol Obstet 2013;287(1):47-52.

[2] Miller ES, Hahn K, Grobman WA. Consequences of a primary elective caesarean delivery across the reproductive life. Obstet Gynecol 2013;121(4):789-97.

[3] Molina G, Weiser TG, Lipsitz SR, et al. Relationship between caesarean delivery rate and maternal and neonatal mortality. JAMA 2015;314(21):2263-70.

[4] Gibbs RS. Clinical risk factors for puerperal infection. Obstet Gynecol 1980;55(Suppl 5):S178-84.

[5] Krieger Y, Walfisch A, Sheiner E. Surgical site infection following caesarean deliveries: trends and risk factors. J Matern Fetal Neonatal Med 2017;30(1):8-12.

[6] Salim R, Braverman M, Teitler N, et al. Risk factors for infections following caesarean delivery: an interventional study. J Matern Neonatal Med 2012;25(12):2708-12.

[7] Awad SS. Adherence to surgical care improvement project measures and post-operative surgical site infections. Surg Infect (Larchmt) 2012;13(4):234-7.

[8] Shah F, Gandhi M, Mehta V, et al. Nosocomical infections in surgical wards. The Internet Journal of Surgery 2009;24(1).

[9] Smaill FM, Grivell RM. Antibiotic prophylaxis versus no prophylaxis for preventing infection after caesarean section. Cochrane Database Syst Rev 2014;(10):CD007482.

[10] Smaill F, Hofmeyr GJ. Antibiotic prophylaxis for caesarean section. Cohrane Database Syst Rev 2002;(3):CD000933.

[11] Chaim W, Bashiri A, Bar-David J, et al. Prevalence and clinical significance of postpartum endometritis and wound infection. Infect Dis Obstet Gynecol 2000;8(2):7782.

[12] Killian CA, Graffunder EM, Vinciguerra TJ, et al. Risk factor for surgical-site infections following caesarean section. Infect Control Hosp Epidemiol 2001;22(10):613-7.

[13] Johnson A, Young D, Reilly J. Caesarean section surgical site infection surveillance. J Hosp Infect 2006;64(1):30-5.

[14] Webster J. Post-caesarean wound infection: a review of the risk factors. Aust $\mathrm{N} \mathrm{Z} \mathrm{J} \mathrm{Obstet} \mathrm{Gynaecol}$ 1988;28(3):201-7.

[15] Mitt P, Lang K, Peri A, et al. Surgical-site infections following caesarean section in an Estonian University hospital: post discharge surveillance and analysis of risk factors. Infect Control Hosp Epidemiol 2005;26(5):44954. 
[16] Litta P, Vita P, de Toffoli JK, et al. Risk factors for complicating infections after caesarean section. Clin Exp Obstet Gynaecol 1995;22(1):71-5.

[17] Beattie PG, Rings TR, Hunter MF, et al. Risk factors for wound infections following caesarean section. Aust N Z J Obstet Gynaecol 1994;34(4):398-402.

[18] Gorbach SL, Bartlett JG, Blacklow NR. Surgical site infections. In: Infectious ciseases. $3^{\text {rd }}$ edn. Lippincott Williams and Wilikins 2004;823-9.

[19] Lilani SP, Jangale N, Chowdhury A. Surgical site infections in clean and clean-contaminated cases. Indian J Med Microbiol 2005;23(4):249-52.
[20] Owen J, Andrews WW. Wound complications after caesarean sections. Clin Obstet Gynecol 1994;37(4):84255.

[21] Satyanarayan V, Prashanth HV, Bhandare B, et al. Study of surgical site infections in abdominal surgeries. J Clin Diagn Res 2011;5(5):935-9.

[22] Gould D. Caesarean section, surgical site infection and wound management. Nurs Stand 2007;21(32):57-62.

[23] Young BC, Hacker MR, Dodge LE, et al. Timing of antibiotic administration and infectious morbidity following caesarean delivery: incorporating policy change into workflow. Arch Gynecol Obstet 2012;285(5):1219-24. 